\title{
Phosphate-Methylated Oligonucleotides Past, Present and Future
}

\author{
Henk M. Buck \\ Kasteel Twikkelerf 94, Tilburg, The Netherlands \\ Email: h.m.buck@ziggo.nl
}

How to cite this paper: Buck, H.M. (2020) Phosphate-Methylated Oligonucleotides Past, Present and Future. Journal of Biophysical Chemistry, 11, 27-42.

https://doi.org/10.4236/jbpc.2020.113003

Received: June 2, 2020

Accepted: August 4, 2020

Published: August 7, 2020

Copyright $\odot 2020$ by author(s) and Scientific Research Publishing Inc. This work is licensed under the Creative Commons Attribution International License (CC BY 4.0).

http://creativecommons.org/licenses/by/4.0/ (c) (i) Open Access

\begin{abstract}
At the moment, we see a great interest for application of Anti Sense Oligonucleotides (ASOs) in order to regulate the expression of genes related to certain diseases. These nucleotides obtained a number of fascinating properties by means of chemical manipulation of natural DNA and RNA under conservation of Watson-Crick base-pairing. About 35 years ago for our research in this field, we selected synthetically (short) phosphate-methylated DNA and RNA. It was concluded that there is an exclusive selection in hybridization affinity with natural DNA and RNA. These (bio)chemical and physical-chemical properties are extensively published. ASOs have found their way in public health as is clearly shown in the treatment of (progressive) neurological diseases. We focus specifically on the past, present and future of the phosphate-methylated oligonucleotides, illustrated with different research studies in chemistry and biophysics. A new field of application of modified DNAs is based on interactive improvements of sensitivity and specificity of nanowire field effect transistor gene chip by designing phosphate-methylated DNA as probe.
\end{abstract}

\section{Keywords}

Anti Sense Oligonucleotides (ASOs), Phosphate-Methylated DNA and RNA, HIV, COVID-19, Neurological Diseases, PCR, Gene Chip

\section{Introduction}

It is known that Anti Sense Oligonucleotides (ASOs) are synthetically prepared (short) single-stranded deoxynucleotide sequences that can block the expression of specific target genes via complementary hybridization [1]. Because of their high specificity there has been growing interest in using them for improving vaccine efficacy. 
The present view is focused on current and future trends of backbone modified phosphate-methylated DNA and RNA. The published (bio)chemical and physical-chemical data demonstrate a number of exclusive properties. These oligonucleotides have shown enhanced duplex stability due to the decrease in electrostatic repulsion between the complementary strands. Manipulated modifications of these oligonucleotides may also cause steric effects (substitution of methyl by ethyl etc.) destabilizing the duplex. An aspect of these modified oligonucleotides is the introduction of chirality at phosphorus resulting in a mixture of diastereoisomers with deviating properties. More different kinds of duplexes can be derived from antiparallel right-handed DNA, non-Watson-Crick base-pairing of oligonucleotides [2], left-handed Z-DNA [3] [4], and more recently F-DNA [5]. The latter DNA structure consists of the modified base 5-formylcytosine (5fC) and might be considered to be the "seventh" base of the genome. Biophysical and structural analysis revealed that this base alters the structure of the DNA double helix and leads to a conformation unique among the known DNA structures. With $\mathrm{X}$-ray, the crystal structure of a self-complementary $5 \mathrm{fC}$ containing dodecamer with three 5fC present in $\mathrm{C}_{\mathrm{P}} \mathrm{G}$ repeats as 5'-CTA5fCG5fCG5fCGTAG-3' shows a clear change in the conformation of the grooves resulting in helical underwinding. Hydrogen reduction results in 5-hydroxymethylcytosine with formation of a B-DNA structure. An interesting aspect of this study is that increase in spermine concentration results in conversion of the 5-formylcytosine containing oligomers into B-DNA. Apparently the shielding of regiospecific phosphate anions plays an important role in this conformational change. Through methylation of the phosphate backbone the coordination via hydrogen networks with phosphate anions will be absent.

In that respect it is noteworthy that the molecular structure of the ammonium salt of the natural $d\left(C_{P} G\right)$ in the crystalline state shows a Z-DNA helix, as was demonstrated by Ramakrishnan and Viswamitra [3]. The crystals were obtained by acetone diffusion technique at $253 \mathrm{~K}$. The four hydrogens of the $\mathrm{NH}_{4}^{+}$cation play a stabilizing role in the organization of different hydrogen networks, suggesting a complex interaction for the formation of a left-handed double helix. The major groove $\mathrm{NH}_{4}^{+}$cation interacts with $\mathrm{N}(7)$ of guanines via water bridges besides making hydrogen bond interactions directly with the anions of the phosphate groups. The $\mathrm{NH}_{4}^{+}$cation located in the minor groove interacts directly with the phosphate anions and water molecules. Symmetry related molecules pack in such a way that the cytosine base stacks on cytosine and guanine base on guanine. This demonstrates that alternating $d\left(C_{P} G\right)$ sequences have the ability to adopt the left handed Z-DNA structure even at the dimer level. A more elaborate study was published before with the hexamer by Wang et al. [4]. This situates the molecular structure of the corresponding phosphate-methylated dimer duplex measured in solution in a unique position. Apparently, besides the shielding of the phosphates and the characteristics of the sugar puckering for a left-handed natural $d\left(C_{P} G\right)$ duplex, the influence of coordination in solution and crystal state is of importance for understanding the dynamics of the $\mathrm{B}-\mathrm{Z}$ 
transition. This shielding results in a decrease of the helix diameter, thus facilitating the anti-syn isomerization of guanine in combination with the conformational change in sugar puckering.

In Figure 1, the effect of covalent shielding is shown with the circular dichroism $(\mathrm{CD})$ spectra of the two left-handed self-complementary phosphate-methylated $d\left(C_{P} G\right) s$ in combination with the two right-handed self-complementary phosphate-methylated $\mathrm{d}\left(\mathrm{G}_{\mathrm{P}} \mathrm{C}\right) \mathrm{s}[6]$.

The difference in chirality of phosphorus in the triester has no influence on the weight of the population densities of the rotamers. The characteristic synconformation of guanine in the Z-form was confirmed with nuclear double resonance. The hybridization stability of the diastereoisomers was obtained with the $1 \mathrm{H}$ NMR chemical shifts vs temperature profiles of the $R_{\mathrm{P}}$ and $S_{\mathrm{P}}$ configurations at a concentration of $3 \times 10^{-3} \mathrm{M}$ for the protons $\mathrm{H} 6(\mathrm{dC})$ and H1' (dG) resulting in a melting transition with sigmoidal shape for these protons at 282 and $286 \mathrm{~K}$, respectively. The corresponding phosphate-methylated $\mathrm{d}\left(\mathrm{G}_{\mathrm{P}} \mathrm{C}\right)$ duplex shows a transition of $300 \mathrm{~K}$ for both configurations. With UV hyperchromicity experiments with all four diastereoisomers at a concentration of $5 \times 10^{-6} \mathrm{M}$ sigmoidal curves were obtained with the corresponding transition values.

With the knowledge of the various chemical and physical parameters, optimal specificity may be achieved leading to further development into various modified nucleotides.

We focus on the past, present and future of the phosphate-methylated oligonucleotides, illustrated with different research studies in chemistry and biophysics.

\section{Results and Discussion}

\subsection{Inhibition of HIV-1 RNA}

A review article about the use of ASOs for vaccine improvement based on the strategy of antigen modification has recently been published [7]. The first attempts

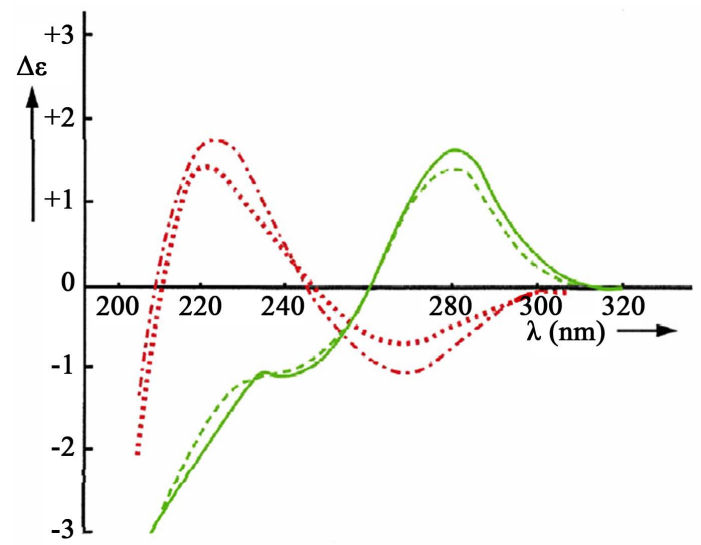

Figure 1. CD spectra of self-complementary phosphate-methylated Z-d $\left(\mathrm{C}_{\mathrm{P}} \mathrm{G}\right)$ for $R_{\mathrm{P}}$ (top) and $S_{\mathrm{P}}$, red curves, and self-complementary phosphate-methylated B-d ( $\mathrm{GP}_{\mathrm{P}} \mathrm{C}$ ) for $R_{\mathrm{P}}$ (top) and $S_{\mathrm{P}}$, green curves, measured in water at $277 \mathrm{~K}$. 
using ASOs for antigen manipulation started in 1990. Goudsmit's group used phosphate-methylated ASOs complementary to the tat responsive region (TAR) of the HIV-1 isolate CBL-4 (RUT) to reduce the viral infectivity [8]. At the same time the corresponding hybridization experiments with the ASOs were published in Science [9]. Technical errors and interpretations in the Science paper as concluded by a university panel resulted in retraction. The results with regard to the HIV-1 tests are not retracted [10].

The research strategy in the Science paper was focused on four target regions TAR, PBS, NEF, and VIF. The selection of the different regions was based on the hairpin loop (single stranded) structures with short RNA fragments. TAR is aimed at the loop area of the transactivator responsive region (bases 15 - 34 and 9132 - 9151), which is essential for transcriptional stimulation by the tat protein. PBS is targeted adjacent to the start site of reverse transcription (bases 162 181). NEF and VIF overlap the start codon of the genes for the regulatory protein nef (bases 8372 - 8391), and the infectivity factor vif (bases 4619 - 4638), respectively [9].

A highly favored structure based on this specific geometry element is TAR with 6 bases AGGGUC in the loop recognition. This was confirmed by the X-ray crystal structure of the TAR loop in complex with tat and the super elongation complex and determined at a resolution of $3.5 \AA$ [11]. The bound TAR loop is stabilized by cross-loop hydrogen bonds. This means that for the inhibition of specific regions relatively short phosphate-methylated DNAs are obvious. In fact earlier hybridization experiments of natural RNA with A-geometry and phosphate-methylated DNA with B-geometry proved that duplex formation is disfavored because of their difference in geometry. Modelling studies showed that adaptation of phosphate-methylated DNA to the A-geometry results in unfavorable steric interactions between adjacent methylated phosphate groups. We demonstrated with model systems that only short phosphate-methylated DNAs are able to hybridize with natural RNA [1].

Unfortunately, in the HIV-1 RNA hybridization experiments 20-nucleotide phosphate-methylated DNAs were used, instead of the (much) shorter ones, which could also be prepared non-automatically, vide infra. The common opinion at that time was that specific inhibition should be more effective with increase of the number of bases, whereas the difference in geometry between the hybridizing nucleotides was the fundamental barrier for duplex formation between phosphate-methylated DNA with B-geometry and HIV-RNA with A-geometry, vide supra.

\subsection{Synthesis of Phosphate-Methylated Oligonucleotides under Different Conditions}

Still the question remains how to place this research on the synthesis of the longer phosphate-methylated DNA in time. For that crucial part we refer to the hexamer phosphate-methylated pyrimidines $\mathrm{d}\left(\mathrm{T}_{\mathrm{O}=\mathrm{POCH} 3} \mathrm{~T}_{\mathrm{O}=\mathrm{POCH} 3} \mathrm{~T}_{\mathrm{O}=\mathrm{POCH}} \mathrm{T}_{\mathrm{O}=\mathrm{POCH} 3} \mathrm{~T}_{\mathrm{O}=\mathrm{POCH} 3} \mathrm{~T}\right)$ and $\left.\mathrm{d}\left(\mathrm{C}_{\mathrm{O}=\mathrm{POCH}} \mathrm{C}_{\mathrm{O}=\mathrm{POCH} 3} \mathrm{C}_{\mathrm{O}=\mathrm{POCH} 3} \mathrm{C}_{\mathrm{O}=\mathrm{POCH}} \mathrm{C}_{\mathrm{O}=\mathrm{POCH}} \mathrm{C}\right)\right)$, and specifically their for- 
mation of parallel duplexes via T-T and C-C base pairs [2]. The natural DNA T-hexamer, obtained via solid-phase chemistry, was directly methylated (using methyl sulfonate) whereas in the case of the C-hexamer first base-protection (using benzoyl chloride-hydrazine) is necessary. With NMR, UV melting transitions and molecular mechanics calculations the parallel duplex for the $\mathrm{T}-\mathrm{T}$ hexamer could be firmly established whereas no parallel C-C hexamer could be determined. In the latter case the chirality of phosphorus is decisive. Structural models of the parallel duplexes with the $S_{\mathrm{P}}$ and $R_{\mathrm{P}}$ configurations of phosphorus showed that methyl groups are forced into the helix groove for $\mathrm{C}-\mathrm{C}$ pairing corresponding with the $R_{\mathrm{P}}$ configuration. In the case of T-T pairing both configurations accommodate the parallel duplex. Using the solid-phase chemistry for the phosphate-methylated dodecamer:

$\mathrm{d}\left(\mathrm{C}_{\mathrm{O}=\mathrm{POCH}} \mathrm{C}_{\mathrm{O}=\mathrm{POCH}} \mathrm{C}_{\mathrm{O}=\mathrm{POCH} 3} \mathrm{C}_{\mathrm{O}=\mathrm{POCH}} \mathrm{C}_{\mathrm{O}=\mathrm{POCH}} \mathrm{C}_{\mathrm{O}=\mathrm{POCH} 3} \mathrm{~T}_{\mathrm{O}=\mathrm{POCH}} \mathrm{T}_{\mathrm{O}=\mathrm{POCH}} \mathrm{T}_{\mathrm{O}=\mathrm{POCH}} \mathrm{T}_{\mathrm{O}=\mathrm{POCH}}\right.$ $\left.\mathrm{T}_{\mathrm{O}=\mathrm{POCH} 3} \mathrm{~T}\right)$ it is, as to be expected, present in the single-strand form. The purity of the phosphate-methylated hexamers and dodecamer was controlled by gel electrophoresis [2].

It seems to us that these results clearly show that formation of parallel DNA duplexes is not simply a matter of shielding of the phosphate-phosphate electrostatic repulsion alone. Apparently the way of accommodation of the methyl groups for both possible configurations on phosphorus together with elimination of phosphate-phosphate repulsions between both strands are decisive with respect to the formation of a parallel DNA duplex.

Based on solution-phase chemistry, the phosphate-methylated dinucleotides $\mathrm{d}\left(\mathrm{T}_{\mathrm{O}=\mathrm{POCH}} \mathrm{T}\right), \mathrm{d}\left(\mathrm{C}_{\mathrm{O}=\mathrm{POCH}} \mathrm{C}\right)$, and $\mathrm{d}\left(\mathrm{T}_{\mathrm{O}=\mathrm{POCH}} \mathrm{C}\right)$ were prepared with both $S_{\mathrm{P}}$ and $R_{\mathrm{P}}$ configurations. All accept the $S_{P}$ configuration for parallel accommodation and d ( $\left.\mathrm{T}_{\mathrm{O}=\mathrm{POCH} 3} \mathrm{~T}\right)$ also for the $R_{P}$ configuration [12].

Even under natural conditions (peptide induced) similar observations for the parallel pyrimidine-pyrimidine bases were made [13]. In these systems the role of the protein has a stereo-selective character that reflects the combination of the phosphate shielding with a stereochemical fit with the duplex. This process of bioconjugation may be considered as an accommodation of autonomic properties resulting in an unexpected duplex form. For the natural DNA oligomers $\mathrm{dC}_{10}, \mathrm{~d}\left(\mathrm{C}_{6} \mathrm{~T}_{6}\right)$, and $\mathrm{d}\left(\mathrm{T}_{6} \mathrm{C}_{2} \mathrm{~T}_{2}\right)$, only the cationic oligopeptide octadeca (L-lysine) $\left(\mathrm{Lys}_{18}\right)$ is able to induce the formation of parallel duplexes with $\mathrm{C}-\mathrm{C}$ and $\mathrm{T}-\mathrm{T}$ base pairs. With octadeca (L-ornithine) $\left(\mathrm{Orn}_{18}\right)$ unfavorable steric interactions are present with the $\mathrm{C}-\mathrm{C}$ base pairs. There is a clear analogy with the corresponding phosphate-methylated DNAs controlled by the $S_{\mathrm{P}}$ and $R_{\mathrm{P}}$ configurations of phosphorus. Thus when cytosine bases are present, parallel duplex formation in both protein-complexated and phosphate-methylated oligomers is possible when the shielding group (ammonium or methyl) links to the sterically most available $\mathrm{O}_{s}$ atom in the phosphate group corresponding with the $S_{\mathrm{p}}$ configuration. In fact this is also the case for the antiparallel phosphate-methylated DNA duplexes (see Figure 4 in [34]). In these cases conformational transmission occurs with widening of the major groove and narrowing of the minor groove. 
This has been observed in changing the helix type from A-DNA via B-DNA into Z-DNA. In the latter case the major groove is nearly flat and the minor groove very narrow and deep.

Exclusive behavior has been established for $\mathrm{d}\left(\mathrm{C}_{\mathrm{O}=\mathrm{POCH} 3} \mathrm{G}\right)$ and $\mathrm{d}\left(\mathrm{G}_{\mathrm{O}=\mathrm{POCH}} \mathrm{C}\right)$. A left-handed Z-DNA and a right-handed B-DNA, respectively, are formed irrespective of the $S_{\mathrm{P}}$ and $R_{\mathrm{P}}$ configuration, vide supra. For the phosphate-methylated $\mathrm{RNA}$ dimer $\mathrm{r}\left(\mathrm{C}_{\mathrm{O}=\mathrm{POCH}} \mathrm{U}\right)$ only the $S_{\mathrm{P}}$ configuration forms a parallel duplex [14]. This result is in good agreement with the corresponding phosphatemethylated pyrimidines on the DNA level. On the other hand the duplex of $\mathrm{r}\left(\mathrm{C}_{\mathrm{O}=\mathrm{POCH}} \mathrm{G}\right)$ is right-handed and the corresponding $\mathrm{d}\left(\mathrm{C}_{\mathrm{O}=\mathrm{POCH}} \mathrm{G}\right)$ is lefthanded [15].

This data clearly shows that introduction of a methyl group as phosphatemethylated in DNA and RNA introduces conformational transitions in the backbone, which results, as clearly demonstrated, in a left-handed DNA structure through base adaptation of $\mathrm{C}$ and $\mathrm{G}$ in an anti- and syn-orientation, respectively.

In most cases the 9-fluorenylmethoxycarbonyl (Fmoc) group was used as the protecting group for the bases [16]. An illustration of the hybridization affinity of the bases with an antiparallel duplex orientation, prepared without using the solid-phase procedure, is shown in Figure 2 [17] [18].

The choice of the interacting phosphate-methylated $\mathrm{dC}_{n}$ with natural $\mathrm{dG}_{k}$, and phosphate-methylated $\mathrm{dA}_{n}$ with $\mathrm{dT}_{k}$ is based on the results obtained for the parallel duplexes of the phosphate-methylated hexamers $\mathrm{dC}_{6}$ and $\mathrm{dT}_{6}$. The reversed combination for phosphate-methylated $\mathrm{dT}_{n}$ with natural $\mathrm{dA}_{k}$ is not possible. For

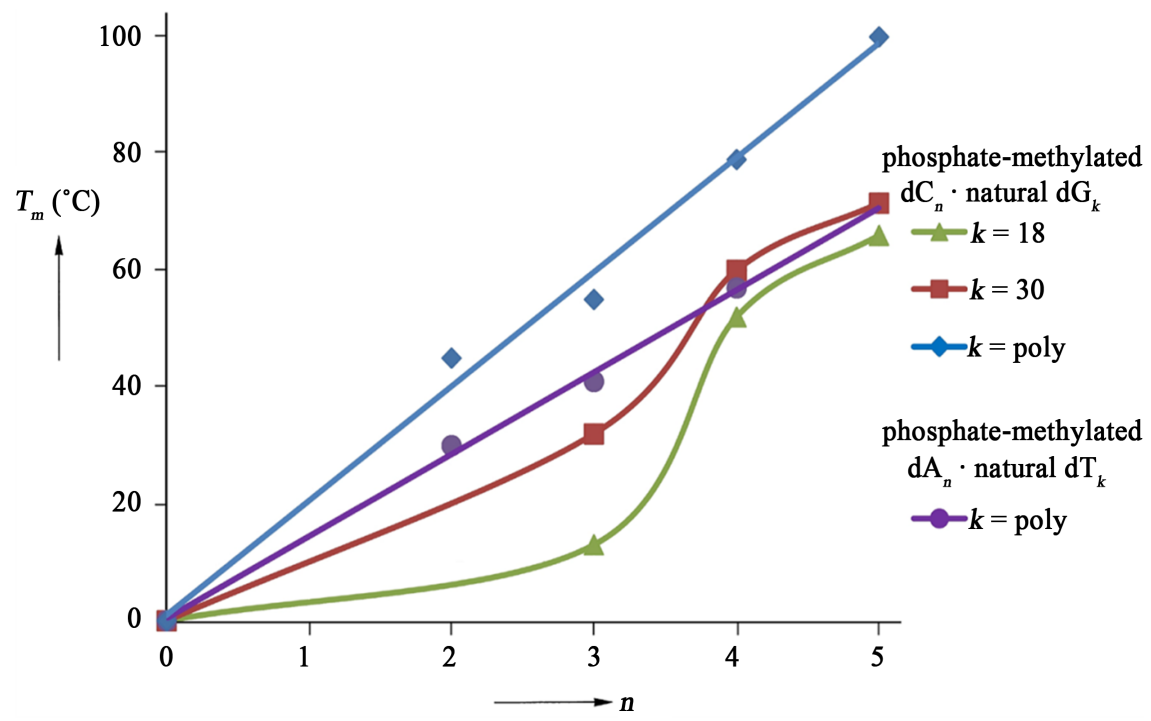

Figure 2. Melting temperature ( $T m$ ) of phosphate-methylated $\mathrm{dC}_{n}$ for $n=2-5$ bases hybridized with its natural complement $\mathrm{dG}_{k}$ for different $k$ values (the numbers are shown in the column) and of phosphate-methylated $\mathrm{dA}_{n}$ for $n=2-5$ bases with poly (dT) without using solid-phase chemistry. Both $T m$-values values for $n=5$ with $k=$ poly are obtained by extrapolation. 
that case we must add an extra number of phosphate-methylated dCs at the beginning or at the end of the strand in question, as demonstrated with the phosphate-methylated dodecamer $\mathrm{d}\left(\mathrm{C}_{6} \mathrm{~T}_{6}\right)$ present in the single-strand form, vide supra.

From earlier publications it is demonstrated that phosphate-methylated DNA hybridizes more strongly with natural DNA in comparison with phosphate-ethylated DNA and methyl phosphonate DNA [1]. With Figure 2 it is clearly shown that a certain numbers phosphate-methylated DNA must be present in the complex formation with the complementary natural strand, affording a cooperative behavior in the hybridization. This is proved with the sigmoidal curves (green and red) of the $T m$-values of phosphate-methylated $\mathrm{dC}_{n}$ for $n=2-5$ bases hybridized with its natural complement $\mathrm{dG}_{k}$ for different $k$ 's. Since the length of the natural DNA is of importance, it is clear that the $T m$-value cannot only be determined by the enthalpy and entropy of base-pair dissociation. This resulted in the conclusion that for phosphate-methylated $\mathrm{dC}_{n}$ for $n=2-5$ bases hybridized with its natural complement $\mathrm{dG}_{b}$ the latter strand adapts its conformation to the modified strand. The importance of the cooperative process is that even short fragments should also be more sensitive for mismatches.

In fact this approach is related to the ability of enzymes to disclose genetic information in the interior of double-stranded DNA. At a first glance it is the enzyme with its positively charged residues, such as lysine and arginine, interacting with the negatively charged phosphate groups that promotes duplex stability. As we mentioned before, the inter-strand repulsion decreases whereas the intra-strand repulsion in one strand is still present resulting in conformational difference between both strands favoring DNA destabilization. Apparently, involvement of one-side interacting enzymes does not result in a cooperative mechanism. So there is a fundamental difference in conformational transmission between covalent and ionic bonding of the natural DNA.

Phosphate-methylated DNA as 8- and 18-mer has been prepared in a study of the regiospecific inhibition of DNA duplication. The procedure for relatively long fragments was based on the following reaction sequence:

natural DNA (solid-phase) $\rightarrow$ base-protection $\rightarrow$ phosphate-methylation $\rightarrow$ base-deprotection

The base-protection was carried out with the Fmoc group [16], the phosphatemethylation with $p$-toluenesulphonyl chloride and methanol, and the base-deprotection with triethylamine [19]. Model proofs, i.e. the regiospecific inhibition of DNA duplication and the $1 \mathrm{H}$ NMR data indicate that the phosphate-backbone is (partially) methylated.

The $E$. coli pab $B$ gene, coding for para-aminobenzoate synthetase, inserted in the M13mp18 phage was used as template for a phosphate-methylated 18and 8-mer (concentration $3 \times 10^{-6} \mathrm{M}$ ), complementary to a pair of selected template regions. The relative synthesis activity along the template strands shows a sharp decrease precisely at the selected region (s) downstream of natura d (AGTAATCACAGCGGGAGA), complementary to the 14 - 31 region: 
-TCTCCCGCTGTGATTACT-, used as the primer for the sequencing reaction. The corresponding phosphate-methylated DNA was unable to act as a primer for Klenow DNA polymerase I. Thus, the Klenow fragment fails to recognize the modified DNA as primer. An arbitrary selected phosphate-methylated d (CTGCTAGAGATTTTCCACAC) has, as to be expected, no impact on the progress of the synthesis. The activity as measured for the 18- and 8-mer at room temperature and $0^{\circ} \mathrm{C}$ respectively, is shown in Figure 3. The 18-mer $\mathrm{d}$ (CACTCACCCATGAACAGC) is complementary to the nucleotide sequence for the -110 - -93 region: -GCTGTTCATGGGTGAGTG- and the 8-mer $\mathrm{d}$ (AGCCTGAC) is complementary to the 1455 - 1462 region: -GTCAGGCT-.

In order to quantify the effect of the inhibition, the density of each band of the sequencing pattern was measured optically. The stop of any synthesis activity after the inhibition region is the result of the absence of a natural primer. For the progress of the duplication after the inhibited regions, the phosphate-methylated DNA should be coupled with a natural fragment complementary with the
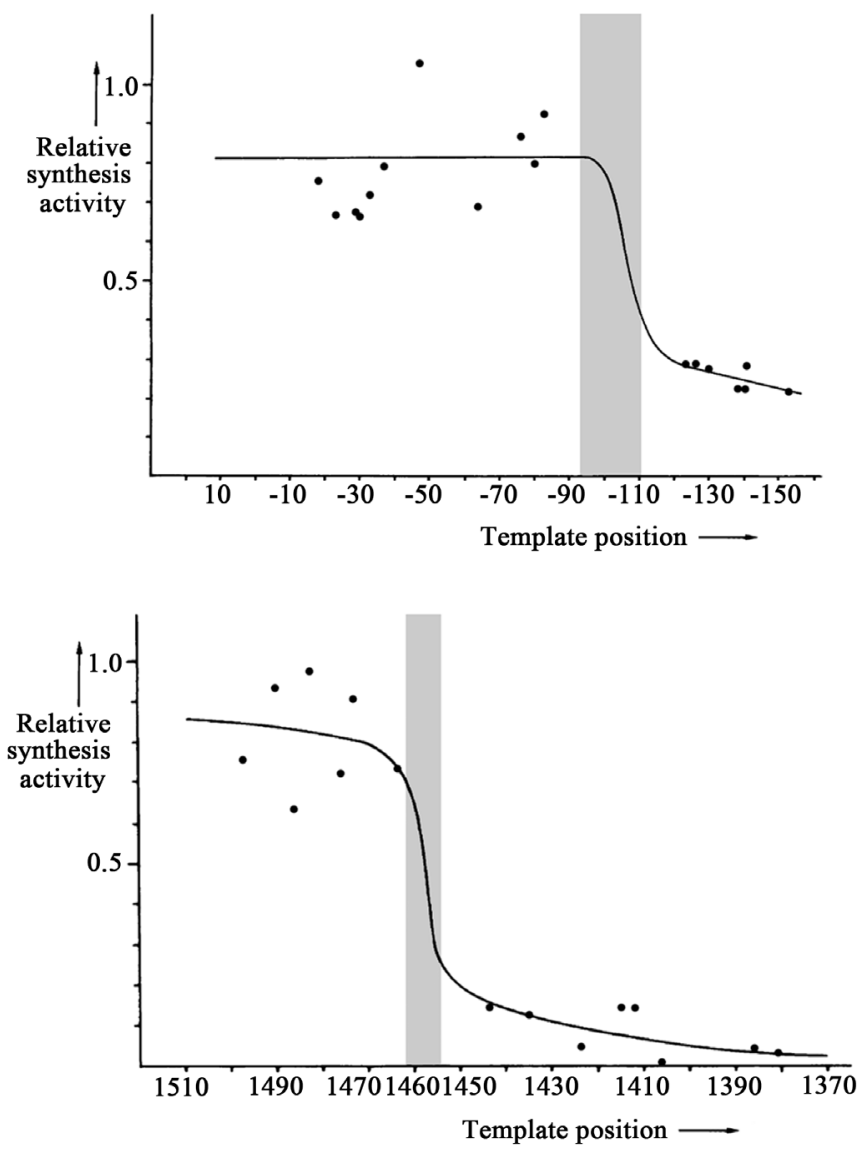

Figure 3. Relative synthesis activity along the template strand. The positions of the phosphate-methylated 18-mer d (CACTCACCCATGAACAGC) complementary to the -110 - -93 region at room temperature (top) and the 8-mer d (AGCCTGAC) complementary to the $1455-1462$ region at $0^{\circ} \mathrm{C}$ (bottom) are indicated. The method for the determination of the relative synthesis activity along the template strand is given in the text. 
nucleotide sequence of the template. This aspect that obtained not much attention in the anti-sense dynamics, may have its repercussions for other neutral backbone-modified DNA's as e.g., methylphosphonates. In that respect it is of interest to take notice of investigations of Song et al., based on structural/sequence motifs in interruption processes of duplication [20] and former conformational studies concerning the allosteric behavior induced by phosphate-methylated DNA on its natural complementary strand.

\subsection{Antisense Oligonucleotides in Public Health}

We also took under consideration processes in relation to the understanding and development of simple DNA and RNA models based on medical treatment, as has been recently suggested in a statement in Science under Public Health: The goal is to steer clear of expensive, complex strategies that require stem cell transplantation, and instead develop affordable, easily administered therapies that would replace or edit genes in the body [21].

In the mid-eighties we started with DNA-based treatments using short wellcharacterized phosphate-methylated trimers as $\mathrm{d}\left(\mathrm{A}_{\mathrm{O}=\mathrm{POCH}} \mathrm{A}_{\mathrm{O}=\mathrm{POCH}} \mathrm{A}\right)$. With UV hyperchromicity we found a $T m$-value of $314 \mathrm{~K}$ for the duplex of the phosphate-methylated trimer with poly (dT) and $293 \mathrm{~K}$ for the natural trimer with poly $(\mathrm{dT})$. In a preliminary experiment we studied the reduction of rat fibroblast cells and the inhibition of human ovarium malign cells. With fibroblast cells with $10^{-5} \mathrm{M}$ trimer the DNA synthesis is markedly retarded with $80 \%$ inhibition (monitored by ${ }^{3} \mathrm{H}$-thymidine uptake). For the inhibition of the ovarium cells the inhibition was $15 \%-20 \%$ with $15 \times 10^{-5} \mathrm{M}$ trimer. In the case of $E$. coli with different cell types complete inhibition was obtained with $10^{-4} \mathrm{M}$. Generally, elongation of the nucleotide will surely enhance selectivity. At that time we had no specific information about the base-sequence of the target DNA. These preliminary experiments are briefly described [22]. Although we were interested in a follow-up of this type of DNA-based medical treatments, our specific attention at that time was asked to focus our research on the inhibition of the HIV-1 virus, vide supra.

Today these ASOs are of importance for the fight against progressive neurological diseases. We will give special attention to the spinal muscular altrophy (SMA), because correspondence with our model systems. SMA refers to several different motor neuron diseases. It is most commonly associated with mutations in the survival motor neuron 1 (SMN1) gene. These mutations are the most frequent genetic cause of death in children. Humans possess a second SMN gene, SMN2. SMN2 and SMN1 are related by an inverted gene duplication. SMN2 contains a C-to-T mutation in exon 7 that redirects alternative splicing to exclude exon 7 and leads to an unstable mature protein that cannot substitute for mutant SMN1. The ASOs are composed of phosphorothioate and 2'-O-methoxyethyl that binds to SMN pre-mRNA to direct alternative splicing and increase inclusion of exon 7 in SMN2. This results in an increase of SMN protein active. For the complete description of these processes: see Corey [23]. 
In contrast with the natural phosphodiester linkages the phosphorothioate modification demonstrates a high degree of metabolic stability and an improved cellular uptake. Corresponding observations have been mentioned for phosphate-methylated DNA and RNA, vide supra. The latter system shows an additional property based on the absence of phosphate-phosphate repulsion in their duplex formation with its complementary strand, vide supra. An illustration of both modified RNAs is given in Figure 4 on the dimer level.

From Figure 4 it is clear that in terms of structure there is a correspondence between both structures. The difference is based on the bonding $\mathrm{POCH}_{3}$ (left, center) and PSNa (right). The latter is mostly described as an ionic structure $\mathrm{PS}^{-} \mathrm{Na}^{+}$. In order to characterize the S-Na bond, we used the rotational spectroscopic data of NaSH [24]. The $r_{0}$ structure of NaSH is $r_{0}(\mathrm{Na}-\mathrm{S})=2.478$ (2) $\AA, r_{0}$ $(\mathrm{S}-\mathrm{H})=1.396$ (7) $\AA$, and bond angle Na-S-H $=92$ (1) degrees. The ab initio calculations gave the equilibrium structure of NaSH as $r_{e}(\mathrm{Na}-\mathrm{S})=2.512 \AA$, $r_{e}(\mathrm{~S}-\mathrm{H})$ $=1.342 \mathrm{~A}$, and bond angle Na-S-H $=93.2$ degrees. Considering that the $r_{0}$ value is usually longer than that of $r_{\mathrm{e}}$, the $a b$ initio calculation estimated shorter length for the S-H bond and longer for the Na-S bond, which is thought to be ionic, than the value derived from the rotational spectroscopic data. The sum of the covalent radii of $\mathrm{Na}$ and $\mathrm{S}$ is $2.56 \mathrm{~A}$. Additional spectroscopic experiments with the other alkali elements $\mathrm{K}, \mathrm{Rb}$, and $\mathrm{Cs}$ show that the increase compared with the Na-S bond comes from the covalent radius difference with Na. From these measurements we come to the conclusion that there is a clear covalent contribution in the Na-S bond. This aspect may be an additional explanation for maintaining solubility in solvents of different polarity. In our opinion there is a good physical-chemical correspondence between the ASO's given in Figure 4.

From earlier data on nucleoside phosphorothioate anions the structural formulas show a double bond between phosphorus and sulfur and a single bond between phosphorus and oxygen with a negative charge localized on oxygen. However, a review of physical data on these compounds resulted in a P-S bond with a single bond and negative charge localized on sulfur, while the P-O bond order for exocyclic and nonbridging oxygens is greater than 1 . These conclusions were based on bond lengths obtained from X-ray crystallographic data and

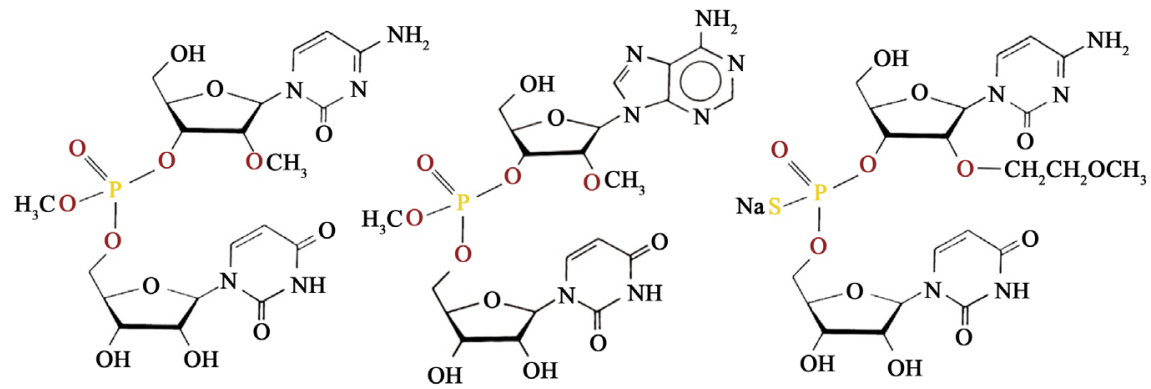

Figure 4. Modified phosphate-methylated RNA dimers (left, center with separate $S_{\mathrm{P}}$ and $R_{\mathrm{P}}$ configurations of phosphorus) [14] and the modified phosphorothioate RNA dimer (right) [23]. 
the magnitudes of the effects of magnetic resonance chemical shifts of phosphorus with labeled oxygens.

In more advanced $\mathrm{MO}$ calculations on e.g. thiobenzophenone it could be calculated that the pronounced electron density on sulfur is the consequence of the relatively small one-center electronic repulsion integral compared with oxygen. With spectroscopic measurements it could be shown that protonation on sulfur resulted in a reduction of the electron donating tendency of SH in comparison with protonation on oxygen resulting in a more pronounced effective charge delocalization of the $\mathrm{SH}$-carbenium ion than for the $\mathrm{OH}$-carbenium ion.

Recently in Science under Insights and Perspectives, promising clinical results have been documented and described: With a growing number of ASO therapeutics being tested in clinical trials, this exciting technology holds the potential to change the therapeutic landscape for many neurological and non-neurological conditions (including cancer, and cardiovascular, infectious, and pulmonary diseases) in the near future [25]. It is to be expected that ASO-based model descriptions may be helpful in Alzheimer disease etc. This is based on earlier energy calculations concerning the implications for the use of the hybridization-arrest technique in this specific disease [26].

It should be emphasized that various physical-chemical aspects are of importance and specifically the molecular conformations of the interacting modified nucleotides.

\subsection{Significance Phosphate-Methylated Oligonucleotides in Future}

The recent results obtained in the eastern part of the world opens a unique facility to compare with the (synthetic) work discussed before.

In fact today the partially and fully phosphate-methylated DNAs can be prepared in various length under solid-phase conditions, as has been recently published [27]:

$$
\begin{aligned}
& \mathrm{NH}_{2}-\mathrm{C}_{6}-\mathrm{C}_{\mathrm{O}=\mathrm{POCH}} \mathrm{A}_{\mathrm{O}=\mathrm{POCH} 3} \mathrm{C}_{\mathrm{O}=\mathrm{POCH}} \mathrm{A}_{\mathrm{O}=\mathrm{POCH}} \mathrm{C}_{\mathrm{O}=\mathrm{POCH}} \mathrm{T}_{\mathrm{O}=\mathrm{POCH}} \mathrm{C}_{\mathrm{O}=\mathrm{POCH} 3} \mathrm{~T}_{\mathrm{O}=\mathrm{POCH}} \mathrm{G} \\
& \mathrm{O}=\mathrm{POCH}_{3} \mathrm{~T}_{\mathrm{O}=\mathrm{POCH}} \mathrm{C}_{\mathrm{O}=\mathrm{POCH}} \mathrm{A}_{\mathrm{O}=\mathrm{POCH}} \mathrm{A}_{\mathrm{O}=\mathrm{POCH}} \mathrm{C}_{\mathrm{O}=\mathrm{POCH}} \mathrm{C}_{\mathrm{O}=\mathrm{POCH}} \mathrm{T}_{\mathrm{O}=\mathrm{POCH}} \mathrm{A}_{\mathrm{O}=\mathrm{POCH}} \mathrm{C} \\
& \mathrm{NH}_{2}-\mathrm{C}_{6}-\mathrm{C}_{\mathrm{O}=\mathrm{POCH}} \mathrm{A}-\mathrm{C}_{\mathrm{O}=\mathrm{POCH}} \mathrm{A}-\mathrm{C}_{\mathrm{O}=\mathrm{POCH}} \mathrm{T}-\mathrm{C}_{\mathrm{O}=\mathrm{POCH}} \mathrm{T}-\mathrm{G}_{\mathrm{O}=\mathrm{POCH}} \mathrm{T}-\mathrm{C}-\mathrm{A}-\mathrm{A}-\mathrm{C}-\mathrm{C}-\mathrm{T}- \\
& \mathrm{A}-\mathrm{C} \\
& \mathrm{NH}_{2}-\mathrm{C}_{6}-\mathrm{C}_{\mathrm{O}=\mathrm{POCH}} \mathrm{A}-\mathrm{C}-\mathrm{A}_{\mathrm{O}=\mathrm{POCH}} \mathrm{C}-\mathrm{T}-\mathrm{C}_{\mathrm{O}=\mathrm{POCH}} \mathrm{T}-\mathrm{G}-\mathrm{T}_{\mathrm{O}=\mathrm{POCH}} \mathrm{C}-\mathrm{A}-\mathrm{A}-\mathrm{C}-\mathrm{C}-\mathrm{T}-\mathrm{A}-\mathrm{C}
\end{aligned}
$$

The corresponding modified RNA systems with an additional modification at the 2'-position (ribose sugar) are of great importance for increased selectivity in the context of treatments based on ASOs. Recently, a new RNA virus was detected known as the Coronavirus (COVID-19). It is an acute respiratory tract infection [28]. An ASO procedure may be applicable if there is more knowledge on the site-specific virus replication. For that case the use of aerosol therapy may provide high local ASOs concentrations with minimal side effects as an attractive option for inhibition [29]. However, great care is required in order to understand the implications of wrong genomic information, vide infra. 
It is well known that the PCR technique is used for the detection and quantification of nucleic acids.

In order to improve specificity and sensitivity, various types of nucleotide-derivative modifications have been introduced, such as peptide nucleic acid (PNA), locked nucleic acid (LNA), and more recently site-specific phosphatemethylated DNA as primer and probe by Lee et al. [30]. Generally, these modified DNAs provide more definite detection results in the case of genetic diagnosis.

An interesting new field is the use of interactive improvements of sensitivity and specificity of nanowire field effect transistor gene chip by designing neutralized DNA, phosphate-methylated DNA, as probe in a whole range of experiments with phosphate-methylated DNAs [27].

\section{Conclusions}

This study was focused on specific trends of the preparation and application of Anti Sens Oligonucleotides (ASOs) in different fields of bio- and medical chemistry. We restricted our scope to a study started 35 years ago on phosphate-methylated DNA and RNA. These oligonucleotides have shown enhanced duplex stability due to the decrease in electrostatic repulsion between the complementary strands. With different physical and biochemical methods it could be concluded that there is an exclusive selection in hybridization affinity with natural DNA and RNA. These (bio)chemical and physical-chemical properties are extensively published. ASOs have also found their way in public health, as is clearly shown in the treatments of various diseases as (progressive) neurological disorders. These ASOs are composed of phosphorothioate and 2'-O-methoxyethyl. In our opinion the phosphate-methylated RNA (see Figure 4) may be a good candidate, because the similarity with natural RNA is eye-catching.

A fundamental aspect in this approach of hybridization is the possibility for inducing a cooperative behavior of the complementary natural strand by the phosphate-methylated DNA. This aspect has been clearly demonstrated in Figure 2 for the sigmoidal curves (green and red) of the $T m$-values of phosphatemethylated $\mathrm{dC}_{n}$ for $n=2-5$ bases hybridized with its natural complement $\mathrm{dG}_{k}$ for different $k$ 's. Apparently this response is achieved by one-side methylation that reduces strongly the inter-strand repulsion. If we are dealing with a selfcomplementary duplex as in the case of phosphate-methylated $d\left(\mathrm{C}_{\mathrm{P}} \mathrm{G}\right)$ s interand intra-strand repulsion is absent resulting in a significant reduction of the helix diameter corresponding with a Z-DNA structure. Similar effects have been realized with cationic (enzymatic) complexation.

In fact today, the partially and fully phosphate-methylated DNAs can be prepared in various length as has been recently published [27] [30].

An interesting approach has been (recently) published by Paul et al. concerning a new route for preparing phosphate-methylated DNAs [31]. They used the oxidative substitution of boranephosphonate diesters as a route to post-synthetically modified DNA. They also emphasized that the introduction of modifications 
into oligonucleotides is important for a large number of applications in the nucleic acids fields. The various physical-chemical aspects are of importance and specifically the molecula $r$ conformations of the interacting modified nucleotides [32] [33].

From recent publications, it is to be expected that phosphate-methylated DNA obtains new perspectives in the field of genetic diagnosis and medical treatments. Generally, nanoelectronics is an important step forward in biology and medicine.

Finally, it is of particular interest to mention the influence of synthetic biology in this field especially focused on the synthesis of the phosphate-methylated DNAs (RNAs). Recently the encoded synthesis of a genetic polymer with an uncharged backbone was published as alkyl phosphonate nucleic acids [35]. The procedure based on chemically manipulated ATP may be useful for the more nature-like phosphate-methylated oligonucleotides. As modified ATPs we can then use $\mathrm{P}$ - $\alpha$-(O-alkyl-phosphonyl)- $\beta$, $\gamma$-diphosphates in which alkyl is methyl (ethyl). The favored one is the methyl group for different steric and stereoelectronic reasons. The argument given for the choice of the preparation of alkyl phosphonate nucleic acids was based on a combination of a close steric and electronic analogy to canonical nucleic acids and therefore provided a tractable challenge for polymerase engineering.

However, in methyl phosphonates it appears that the presence of a P-C bond disturbs the helix conformation for stereoelectronic reasons. This leads to a weaker hybridization with DNA and RNA for $\mathrm{n}>4$ : see Figure 3 in [22]. Phosphate-methylated oligonucleotides are found to have an optimal combination of steric and stereoelectronic factors, and form the strongest hybrids with natural DNA [1].

\section{Conflicts of Interest}

The author declares no conflicts of interest regarding the publication of this paper.

\section{References}

[1] Van Genderen, M.H.P., Koole, L.H. and Buck, H.M. (1989) Hybridization of Phosphate-Methylated DNA and Natural Oligonucleotides. Implications for ProteinInduced DNA Duplex Stabilization. Recueil des Travaux Chimiques des Pays-Bas, 108, 28-32. https://doi.org/10.1002/recl.19891080106

[2] Koole, L.H., van Genderen, M.H.P. and Buck, H.M. (1987) A Parallel Right-Handed Duplex of the Hexamer $\mathrm{d}\left(\mathrm{T}_{\mathrm{P}} \mathrm{T}_{\mathrm{P}} \mathrm{T}_{\mathrm{P}} \mathrm{T}_{\mathrm{P}} \mathrm{T}_{\mathrm{P}} \mathrm{T}\right)$ with Phosphate Triester Linkages. Journal of the American Chemical Society, 109, 3916-3921. https://doi.org/10.1021/ja00247a015

[3] Ramakrishnan, B. (1988) Crystal and Molecular Structure of the Ammonium Salt of the Dinucleoside Monophosphate $\mathrm{d}\left(\mathrm{C}_{\mathrm{P}} \mathrm{G}\right)$. Journal of Biomolecular Structure and Dynamics, 6, 511-523. https://doi.org/10.1080/07391102.1988.10506504

[4] Wang, A.H.-J., Quigley, G.J., Kolpak, F.J., van der Marel, G., van Boom, J.H. and Rich, A. (1981) Left-Handed Double Helical DNA: Variations in the Backbone Con- 
formation. Science, 211, 171-176. https://doi.org/10.1126/science.7444458

[5] Raiber, E.-A., Murat, P., Chirgadze, D.Y., Beraldi, D., Luisi, B.F. and Balasubramanian, S. (2015) 5-Formylcytosine Alters the Structure of the DNA Double Helix. Nature Structural \& Molecular Biology, 22, 44-49. https://doi.org/10.1038/nsmb.2936

[6] Quaedflieg, P.J.L.M., Koole, L.H., van Genderen, M.H.P. and Buck, H.M. (1989) A Structural Study of Phosphate-Methylated $\mathrm{d}\left(\mathrm{C}_{\mathrm{P}} \mathrm{G}\right)_{n}$ and $\mathrm{d}\left(\mathrm{G}_{\mathrm{P}} \mathrm{C}\right)_{n}$ DNA Oligomers. Implication of Phosphate Shielding for the Isomerization of B-DNA into Z-DNA. Recueil des Travaux Chimiques des Pays-Bas, 108, 421-423. https://doi.org/10.1002/recl.19891081107

[7] Batista-Duharte, A., Sendra, L., Herrero, M.J., Téllez-Martínez, D., Carlos, I.Z. and Salvador, F.A. (2020) Progress in the Use of Antisense Oligonucleotides for Vaccine Improvement. Biomolecules, 10, 316. https://doi.org/10.3390/biom10020316

[8] Goudsmit, J., Geelen, J., Keulen, W., Notermans, D., Kuiken, C., Ramautarsing, C., Smit, L., Koole, L., van Genderen, M., Buck, H., Sninsky, J. and Krone, W. (1990) Characterization of the African HIV-1 Isolate CBL-4 (RUT) by Partial Sequence Analysis and Virus Neutralization with Peptide Antibody and Antisense PhosphateMethylated DNA. AIDS, 4, 559-564. https://doi.org/10.1097/00002030-199006000-00010

[9] Buck, H.M., Koole, L.H., van Genderen, M.H.P., Smit, L., Geelen, J.L.M.C. and Goudsmit, J. (1990) Phosphate-Methylated DNA Aimed at HIV-1 RNA Loops and Integrated DNA Inhibits Viral Infectivity. Science, 248, 208-212.

https://doi.org/10.1126/science.2326635

[10] Moody, H.M., Quaedflieg, P.J.L.M., Koole, L.H., van Genderen, M.H.P., Buck, H.M., Smit, L., Jurriaans, S., Geelen, J.L.M.C. and Goudsmit, J. (1990) Inhibition of HIV-1 Infectivity by Phosphate-Methylated DNA: Retraction. Science, 250, 125-126. https://doi.org/10.1126/science.2218505

[11] Schulze-Gahmen, U. and Hurley, J.H. (2018) Structural Mechanism for HIV-1 TAR Loop Recognition by Tat and the Super Elongation Complex. Proceedings of the National Academy of Sciences of the United States of America, 115, 12973-12978. https://doi.org/10.1073/pnas.1806438115

[12] Quaedflieg, P.J.L.M., Broeders, N.L.H.L., Koole, L.H., van Genderen, M.H.P. and Buck, H.M. (1990) Conformation of the Phosphate-Methylated DNA Dinucleotides $\mathrm{d}\left(\mathrm{C}_{\mathrm{P}} \mathrm{C}\right)$ and $\mathrm{d}\left(\mathrm{T}_{\mathrm{P}} \mathrm{C}\right)$. Formation of a Parallel Miniduplex Exclusively for the $S$ Configuration at Phosphorus. The Journal of Organic Chemistry, 55, 122-127. https://doi.org/10.1021/jo00288a025

[13] Van Genderen, M.H.P., Hilbers, Koole, L.H. and Buck, H.M. (1990) Peptide-Induced Parallel DNA Duplexes for Oligopyrimidines. Stereospecificity in Complexation for Oligo (L-lysine) and Oligo (L-ornithine). Biochemistry, 29, 7838-7845. https://doi.org/10.1021/bi00486a009

[14] Van Genderen, M.H.P., van der Heiden, A.P., Koole, L.H., van Genderen, M.H.P., Coenen, A.J.M., van der Wal, S. and Buck, H.M. (1990) Synthesis and Conformation of Phosphate-Methylated $r\left(\mathrm{C}_{P} \mathrm{U}\right)$ and $\mathrm{r}\left(\mathrm{A}_{\mathrm{P}} \mathrm{U}\right)$. Formation of a Prallel RightHanded Duplex for $S_{\mathrm{P}} \mathrm{r}\left(\mathrm{C}_{\mathrm{P}} \mathrm{U}\right)$. Proceedings of the Koninklijke Nederlandse Akademie van Wetenschappen, 93, 33-38.

[15] Buck, H.M. (2017) Modified RNA with a Phosphate-Methylated Backbone. A Serious Omission in Our (Retracted) Study at HIV-1 RNA Loops and Integrated DNA. Specific Properties of the (Modified) RNA and DNA Dimers. Journal of Biophysical Chemistry, 7, 9-25.

[16] Koole, L.H., Moody, H.M., Broeders, N.L.H.L., Quaedflieg, P.J.L.M., Kuijpers, 
W.H.A., Van Genderen, M.H.P., Coenen, A.J.J.M., Van der Wal, S. and Buck, H.M. (1989) Synthesis of Phosphate-Methylated DNA Fragments Using 9-Fluorenylmethoxycarbonyl as Transient Base Protecting Group. The Journal of Organic Chemistry, 54, 1657-1664. https://doi.org/10.1021/jo00268a030

[17] Buck, H.M. (1996) Phosphate-Methylated DNA: A Unique Oligonucleotide as with Other Modified DNAs. Proceedings of the Koninklijke Nederlandse Akademie van Wetenschappen, 99, 145-153.

[18] Buck, H.M. (1997) The Impact of Chirality of Phosphorus in Methylphosphotriester DNA on Duplex Formation and Its Significance for Inducing Methylation-Resistance Genes. Proceedings of the Koninklijke Nederlandse Akademie van Wetenschappen, 100, 1-9.

[19] Moody, H.M., van Genderen, M.H.P., Koole, L.H., Kocken, H.J.M., Meijer, E.M. and Buck, H.M. (1989) Regiospecific Inhibition of DNA Duplication by Antisense Phosphate-Methylated Oligodeoxynucleotides. Nucleic Acids Research, 17, 47694782. https://doi.org/10.1093/nar/17.12.4769

[20] Song, W., Dominska, M., Greenwell, P.W. and Petes, T.D. (2014) Genome-Wide High Resolution Mapping of Chromosome Fragile Sites in Saccharomyces cerevisiae. Proceedings of the National Academy of Sciences of the United States of America, 111, E210-E2218. https://doi.org/10.1073/pnas.1406847111

[21] Cohen, J. and Kaiser, J. (2019) Gates and NIH Join Forces on HIV and Sickle Cell Diseases. Science, 366, 558-559. https://doi.org/10.1126/science.366.6465.558-b

[22] EP0358657B1 (1993) Poly(deoxyribonucleotides), Pharmaceutical Compositions, Use and Preparation of the Poly(deoxyribonucleotides).

[23] Corey, D.R. (2017) Nusinersen, an Antisense Oligonucleotide Drug for Spiral Muscular Atrophy. Nature Neuroscience, 20, 479-499. https://doi.org/10.1038/nn.4508

[24] Kagle, E. and Kawaguchi, K. (1997) Laboratory Detection and Rotational Rest Frequencies of NaSH. ApJ, 491, L129-L132. https://doi.org/10.1086/311069

[25] Leavitt, B.R. and Tabrizi, S.J. (2020) Antisense Oligonucleotides for Neurodegeneration. Science, 367, 1428-1429. https://doi.org/10.1126/science.aba4624

[26] Van Genderen, M.H.P., van Hommerig, S.A.M. and Buck, H.M. (1990) Loop Formation in a DNA Duplex by Hybridization with a Phosphate-Methylated DNA Oligomer. Implications for the Use of the Hybridization-Arrest Technique in Alzheimer's Disease. Proceedings of the Koninklijke Nederlandse Akademie van Wetenschappen, 93, 21-28.

[27] Hu, W.P., Tsai, C.C., Yang, Y.-S., Chan, H.W.-H. and Chen, W.-Y. (2018) Synergetic Improvements of Sensitivity and Specificity of Nanowire Field Effect Transistor Gene Chip by Designing Neutral DNA as Probe. Scientific Reports, 8, Article No. 12598. https://doi.org/10.1038/s41598-018-30996-4

[28] Wölfe, R., Corman, V.M., Guggemos, W., Seilmaier, M., Zange, S., Müller, M.A., Niemeyer, D., Jones T.C., Vollmar, P., Rothe, C., Hoelscher, M., Bleicker, T., Brünink, S., Schneider, J., Ehmann, R., Zwirglmaier, K., Drosten, C. and Wendtner, C. (2020) Virological Assessment of Hospitalized Patients with COVID-2019. Nature. https://doi.org/10.1038/s41586-020-2196-x

[29] Chandel, A., Goyal, A.K., Ghosh, G. and Rath, G. (2019) Recent Advances in Aerosolised Drug Delivery. Biomedicine \& Pharmacotherapy, 112, Article ID: 108601. https://doi.org/10.1016/j.biopha.2019.108601

[30] Li, T.-L., Wu, M.-W., Lin, W.-C., Lai, C.-H., Chang, Y.-H., Su, L.-J. and Chen, W.-Y. (2019) Designed Phosphate-Methylated Oligonucleotides as PCR Primers for SNP Discrimination. Analytical and Bioanalytical Chemistry, 411, 3871-3880. 
https://doi.org/10.1007/s00216-019-01865-4

[31] Paul, S., Roy, S., Monfregola, L., Shang, S., Shoemaker, R. and Caruthers, M.H. (2015) Oxidative Substitution of Boranephosphonate Diesters as a Route to PostSynthetically Modified DNA. Journal of the American Chemical Society, 137, 32533264. https://doi.org/10.1021/ja511145h

[32] Kuo, T.-C., Wu, M.-W., Lin, W.-C., Matulis, D., Yang, Y.-S., Li, S.-Y. and Chen, W.-Y. (2020) Reduction of Interstrand Charge Repulsion of DNA Duplexes by Salts and by Neutral Phosphotriesters. Contrary Effects for Harnessing Duplex Formation. Journal of the Taiwan Institute of Chemical Engineers.

https://doi.org/10.1016/j.jtice.2020.02.023

[33] Tsubaki, K., Hammill, M.L., Varley, A.J., Kitamura, M., Okauchi, T. and Desaulniers, J.-P. (2020) Synthesis and Evaluation of Neutral Phosphate Triester Bacbone Modified SiRNAs. ACS Medicinal Chemistry Letters.

https://doi.org/10.1021/acsmedchemlett.0c00232

[34] Buck, H.M. (2015) Retracted HIV Study Provides New Information about the Status of the in Vitro Inhibition of DNA Replication by Backbone Methylation. Journal of Biophysical Chemistry, 6, 29-34. https://doi.org/10.4236/jbpc.2015.61003

[35] Arangundy-Franklin, S., Taylor, A.I., Porebski, B.T., Genna, V., Peak-Chew, S., Vaisman, A., Woodgate, R., Orozco, M. and Holliger, P. (2019) A Synthetic Genetic Polymer with an Uncharged Backbone Chemistry Based on Alkylphosphonate Nucleic Acids. Nature Chemistry, 11, 533-542. 